\title{
Periodic Microstructures Formation on Plastic Plate by Aerosol Beam Irradiation
}

\author{
Masahiro TSUKAMOTO*, Nobuyuki ABE*, Junji MORIMOTO** and Jun AKEDO***
}

(Received September 27, 2010)

\begin{abstract}
Technology of periodic microstructures formation on plastic plate, the polyethylene terephthalate (PET) plate, was developed with an aerosol beam. The beam was composed of submicron-size anatase titania $\left(\mathrm{TiO}_{2}\right)$ particles. Formation mechanism depended on an incident angle of the beam to the PET plate. At an incident angles in the range of 0 to $30^{\circ}$, a $\mathrm{TiO}_{2}$ films were fabricated on the PET plate. Deposition rate of the film decreased as incident angle increased in the range of 0 to $30^{\circ}$. The film was not produced at $40^{\circ}$. At 50 and $60^{\circ}$, the PET plate was etched by the beam irradiation. In the etching area, periodic microstructures were self-organized, whose grooves' direction was perpendicular to the beam incidence direction.
\end{abstract}

Key Words: Periodic Microstructure, Titania, Polyethylene Terephtalate, PET, Film Formation, Aerosol, Aerosol Beam

\section{Introduction}

Coating technology using an aerosol beam was developed and has already been effectively applied to the functional ceramics film formation ${ }^{1-8)}$. The aerosol beam was composed of submicron size functional ceramics particles accelerated by gas flow to velocities of several hundred meters per second. When the substrate was irradiated with the aerosol beam, the particles collided with the substrate and formed the film. The crystal structure of the particles can be retained since neither the particles nor the substrate are heated during the aerosol beam irradiation. In our previous study, hydroxyapatite films were created on the plastic plate by this technology ${ }^{8}$. At an oblique incidence in this process, a force is generated parallel to the surface in addition to the normal vector. This force acting parallel to the surface etched the plastic plate surface ${ }^{8)}$. This result suggested that the aerosol beam can be used for microstructures formation on the plastic surface by the etching process in addition to the film formation.

In this study, to investigate the etching phenomena due to aerosol beam irradiation, the plastic plates were irradiated with an aerosol beam at incident angles in the 0 to $60^{\circ}$ range. The polyethylene terephtalate (PET) and anatase type titania $\left(\mathrm{TiO}_{2}\right)$ powders were used as a plastic plate and particles of the aerosol beam, respectively. Anatase type is an attractive material for applications such as photocatalyst. The $\mathrm{TiO}_{2}$ photocatalyst decomposes organic compounds under ultraviolet irradiation. The $\mathrm{TiO}_{2}$ particles' average size was about $200 \mathrm{~nm}$ and a roughness of the PET plate was around $0.04 \mu \mathrm{m}$.

\section{Experimental}

The aerosol beam irradiation system was primarily composed of an aerosol chamber with a processing chamber connected by a Teflon tube ${ }^{1-8)}$. An aerosol was produced by mixing the $\mathrm{TiO}_{2}$ particles with helium (He) gas using a vibration system. The processing chamber was pumped down with a mechanical booster pump and a rotary pump to produce a He gas flow from the aerosol chamber to the processing chamber. The $\mathrm{TiO}_{2}$ particles accelerated by the flow of He gas were carried to the processing chamber through the Teflon tube and nozzle. During the experiments, the pressure difference between the two chambers was $1 \mathrm{~atm}$. The nozzle employed in this experiment had a rectangular orifice of $6.0 \times 0.3 \mathrm{~mm}$. Schematic diagram of the aerosol beam irradiation on the PET plate is shown in Fig. 1. As shown in Fig. 1, the aerosol beam ejected from the nozzle

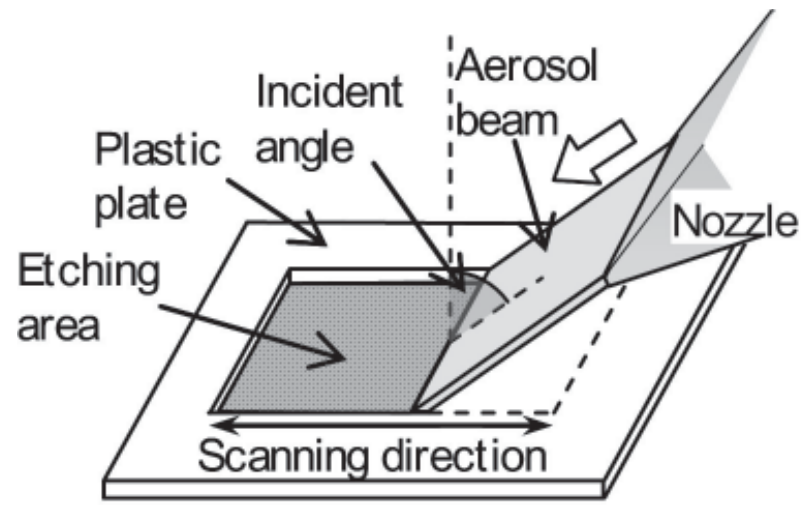

Fig.1 The aerosol beam ejected from the nozzle irradiated the plate.

* Joining and Welding Research Institute, Osaka University (Mihogaoka, Ibaraki, Osaka 567-0047, Japan)

* * Kinki University (3-4-1 Kowakae, Higashi-Osaka, Osaka 577-8502, Japan)

* * National Institute of Advanced Industrial Science and Technology (1-2 Namiki, Tsukuba, Ibaraki 305-8564, Japan) 


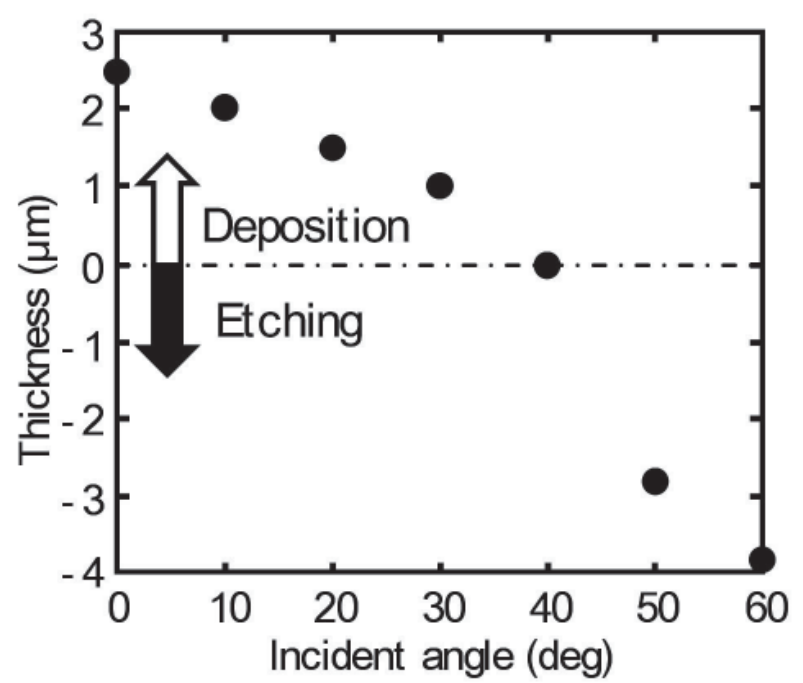

Fig.2 The thickness of the $\mathrm{TiO}_{2}$ films produced with the aerosol beam at incident angles in the 0 to $30^{\circ}$ range and the etching depth of the PET plate in the 50 to $60^{\circ}$ range.

irradiated the plate. The distance between the nozzle and the PET plate was $10 \mathrm{~mm}$. The incident angle of the aerosol beam was varied from 0 to $60^{\circ}$ with a period of $10^{\circ}$ by rotation of the $\theta$ stage. The PET plate's position was controlled with XYZ stages connected to a computer. An area of $6.0 \times 5.0 \mathrm{~mm}$ on the surface of the PET plate was scanned by the aerosol beam at a scanning velocity of $1.5 \mathrm{~mm} / \mathrm{s}$ at room temperature. Neither the PET plate nor the $\mathrm{TiO}_{2}$ particles were heated during the aerosol beam irradiation.

The PET plate surface irradiated with the aerosol beam was analyzed with a surface profiler, an optical microscope, a scanning electron microscope (SEM), laser scanning microscope (LSM), atomic force microscope (AFM) and an electron probe micro analyzer (EPMA). Photocatalytic effect of the aerosolbeam-etched PET plate was examined to investigate the residue of the $\mathrm{TiO}_{2}$ particles in the etching area. For this examination, decomposition of acetaldehyde was performed with the PET plate illuminated with ultraviolet light. Concentration of acetaldehyde was measured with detecting tube.

\section{Results and Discussion}

Figure 2 shows the thickness of the $\mathrm{TiO}_{2}$ films produced with the aerosol beam at incident angles in the 0 to $30^{\circ}$ range and the etching depth of the PET plate in the 50 to $60^{\circ}$ range. As Fig. 2 shows, $\mathrm{TiO}_{2}$ film was formed in the 0 to $30^{\circ}$ range and the thickness decreased as an incident angle increased. At the $40^{\circ}$, $\mathrm{TiO}_{2}$ film was not formed at all. In the 50 to $60^{\circ}$ range, PET plate was etched and the etching depth increased as an incident

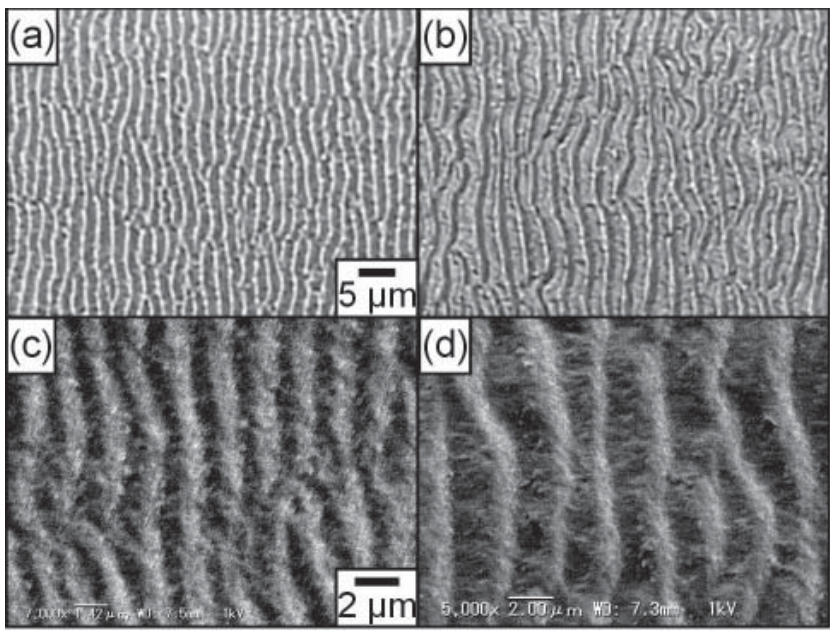

Fig.3 Surface images of the PET plate formed at 50 and $60^{\circ}$ observed with an optical microscope ((a), (b)) and a scanning electron microscope ((c), (d)).

angle increased. Surface images of the PET plate formed at 50 and $60^{\circ}$ observed with an optical microscope are shown in Figs. 3(a) and 3(b), respectively. SEM images of the PET surface for 50 and $60^{\circ}$ are shown in Figs. 3(c) and 3(d), respectively. As Figs. 3(a), 3(b), 3(c) and 3(d) show, periodic microstructures were produced in the etching area. The direction of the grooves of the periodic microstructures was perpendicular to the beam incidence direction. The periods of the periodic microstructures formed at 50 and $60^{\circ}$ were 1.8 and $2.8 \mu \mathrm{m}$, respectively. Depth from the peak of the hill to the bottom of the groove was in the 380 to $630 \mathrm{~nm}$ range, which was measured with LSM and AFM. When the aerosol beam did not scan an area on the PET surface, the periodic microstructures with the periods of 1.8 and $2.8 \mu \mathrm{m}$ were created in the irradiation region at the beam incident angles of 50 and $60^{\circ}$, respectively. This indicates that fluctuation of the stage motion for the aerosol beam scanning was not relation to the mechanism of the periodic microstructure formation. The periods of 1.8 and $2.8 \mu \mathrm{m}$ were much shorter than width of the nozzle's rectangular orifice, $300 \mu \mathrm{m}$. Thus, the periodic microstructures were self-organized in the aerosol beam irradiation area. These results suggested that local flow of $\mathrm{TiO}_{2}$ particles generated on the direction axis of the aerosol beam incidence produce the grooves of the periodic microstructures as shown in Fig. 4. The local flow of $\mathrm{TiO}_{2}$ particles required for the periodic microstructure formation might be caused by the local He gas flow since the particles' behavior depends on the He gas flow. It is probable that micro scratches produced by the particles' impacts at the initial stage of the aerosol beam irradiation induced the local He gas flow generation. However, the actual mechanism of the local 


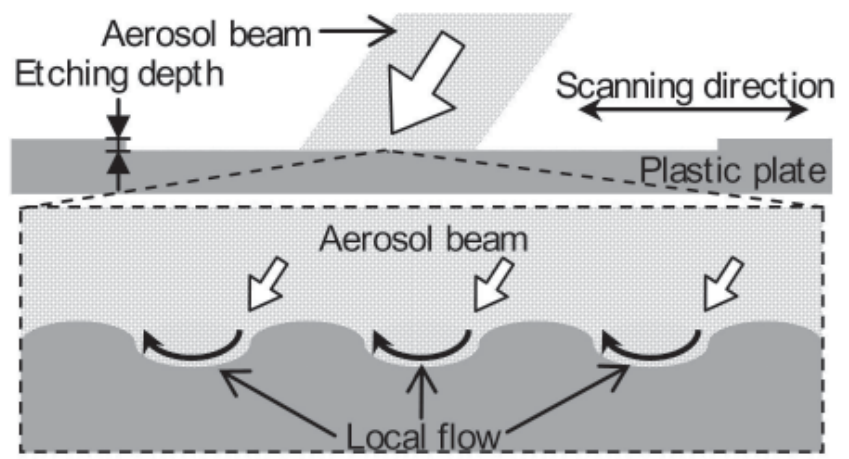

Fig.4 Local flow of $\mathrm{TiO}_{2}$ particles generated on the direction axis of the aerosol beam incidence produce the grooves of the periodic microstructures.

He gas flow generation has not been elucidated. It is intended to report more detailed analysis of the periodic microstructures since additional measurements and theory on the local He gas flow generation are required.

Titanium (Ti) signal image was detected in the periodic microstructure formation area with EPMA. This image indicated that Ti signal was distributed in the grooves of periodic microstructures. In the examinations of photocatalytic effect, concentration of the acetaldehyde was decreased. This reduction indicated that acetaldehyde was decomposed with the aerosolbeam-etched PET plate. These results of EPMA analysis and examinations of photocatalytic effect suggest that $\mathrm{TiO}_{2}$ particles were remained in the grooves of the periodic microstructures.

\section{Conclusions}

We developed a technology of the periodic microstructures formation on the PET plate with an aerosol beam. The periodic structures were self-organized at oblique incidence of the aerosol beam in the incident angle range of 50 to $60^{\circ}$. The period of the periodic microstructures was about 1.8 and $2.8 \mu \mathrm{m}$ at 50 and $60^{\circ}$ of the incident angles, respectively. The grooves of the periodic microstructures lied perpendicular to the direction vector of the aerosol beam.

\section{Reference}

1) A. Fujishima and K. Honda: Bull. Chem. Soc. Jpn., 44 (1971) 1148 1150.

2) A. Fujishima and K. Honda: Nature, 238 (1972) 37 - 38.

3) A. Tiselius, S. Hjertén and Ö. Levin: Arch. Biochem. Biophy., 65 (1956) 132 - 155.

4) T. Fujihara, M. Tsukamoto N. Abe, S. Miyake, T. Ohji and J. Akedo: Trans. Mater. Res. Soc. Jpn., 30 (2005) 1017 - 1020.

5) J. Akedo, M. Ichiki, K. Kikuchi and R. Maeda: Sens. Actuators A, 69 (1998) 106 - 112

6) M. Tsukamoto, T. Fujihara, N. Abe, S. Miyake, M. Katto, T. Nakayama and J. Akedo: Jpn. J. Appl. Phys., 42 (2003) L120 - L122.

7) T. Fujihara, M. Tsukamoto N. Abe, S. Miyake, T. Ohji and J. Akedo: Vacuum, 73 (2004) 629 - 633.

8) M. Tsukamoto, N. Nakamura, A. Kitajima, J. Morimoto, N. Abe, J. Akedo: Jpn. J. Appl. Phys., 45 (2006) 7840 - 7844. 